\title{
A Quantitative Survey on the knowledge and use of Contraceptive among women in Delta State, Nigeria
}

\author{
Aronu, C. O ${ }^{1}$. Oti, E. $\mathbf{U}^{2}$. Oguagbaka, S. K. ${ }^{3}$ and Okoh, L. M. ${ }^{4}$ \\ ${ }^{1}$ Department of Statistics, Chukwuemeka Odumegwu Ojukwu University, Anambra State \\ 2 Department of Statistics, Federal Polytechnic Ekowe, Bayelsa State, Nigeria \\ ${ }^{3}$ Department of Statistics, Federal Polytechnic, Oko, Anambra State, Nigeria \\ ${ }^{4}$ Department of Computer Science, Delta State Polytechnic, Otefe-Oghara, Delta State, Nigeria
}

\begin{abstract}
This study examines the knowledge and use of contraceptive amongst women in Oghara, Delta, State, Nigeria. The objectives of the study include: to determine the demographic variables that impact on the knowledge and usage of Contraceptive among women, to identify the medium adopted to acquire knowledge of Contraceptive among women, and to ascertain the Contraceptive method used by women. The source of data for the study was the primary source of data collection with the aid of a questionnaire administered to the target population. The statistical tools used in this study were the Logistic regression analysis and Descriptive Statistics. The findings of the study for the descriptive analysis of the demographic responses showed that majority of the respondents were aged 30-34 while the majority of the respondents were married, the majority of the respondents had secondary education. It was found that the overall misclassification rate of knowledge of contraceptive among the respondents was $38.2 \%$ while the overall misclassification on use of contraceptive was $17.3 \%$ which implies that the response from the respondents on knowledge and use of contraceptive were reliable. Also, findings showed that demographic variables such as Age of respondents and response on the desired number of children contributed significantly to the status of knowledge of contraceptive amongst women. Further findings revealed that demographic variables such as Marital Status of respondents, Religion, and the highest level of education contributed significantly to the status of use of contraceptives amongst women.
\end{abstract}

Keywords: Age, Contraceptives, Demographic variables, Marital Status, Misclassification.

\section{INTRODUCTION}

In Nigeria, 50\% of women aged 15-49 reported unplanned pregnancies resulting in unsafe abortion in 10\% (Bankole et al., 2006). An estimated 760,000 induced abortions occur annually (Abiodun and Balogun, 2009) accounting for 20\%- $40 \%$ of maternal deaths (Monjok et al., 2010). Unintended pregnancies are also associated with smoking, drinking, physical abuse (Blumenthal et al, 2011), depression (Tsui et al, 2010), school dropout or disruption (Rich-Edwards, 2002), poor antenatal attendance and obstetric outcomes, low birth weight and developmental deficits (Blumenthal et al, 2011). Resentment of the baby may lead to neglect (Tsui et al, 2010; Oringanje et al., 2009). Economic costs from disrupted schooling can worsen poverty due to unemployment from low level of skills, and government spends on welfare and skill acquisition programs (Rich-Edwards, 2002). Poverty may become a vicious cycle as offspring themselves may have unintended pregnancies, and become victims of physical abuse (Oringanje et al., 2009).High fertility rates and low usage of contraceptive have remained a major problem in Nigeria. Past studies on contraceptive use in Nigeria have continued to link the use of contraceptive to social economic conditions, proximity to health facilities and exposure to knowledge on family planning. These studies did this by comparing the contraceptive behavior of mostly students and in the South West and North Central of Nigeria and none of these studies considered women in the SouthSouth of Nigeria. Hence, there exist little literature on women who are out of school or whom have not attended school before in Nigeria. Therefore, the present study intends to close this gap by assessing the knowledge and use of Contraceptive among women in Oghara, Delta State. 
Aronu, C. O. et. al., A Quantitative Survey on the knowledge and use of Contraceptive ......

\section{LITERATURE REVIEW}

Stephenson et al. (2007) in their study assessed the role of community facilitators in explaining geographic variations in modern contraceptive use in Sub-Saharan Africa. Data from demographic health surveys from the six countries was used. The findings of the study showed that there was a significant relationship between community facilitators and the use of modern contraceptives. In addition it was noted that community facilitators contributed to increasing awareness among the potential users on the availability, importance and possible side effects of family planning services.

Tsui et al. (2009) explored the patterns and trends in adolescent contraceptive use and discontinuation in developing countries using demographic and health survey data from more than 40 countries. The objective of their study was to examine the rates of contraceptive adoption, discontinuation and switching trends among married and unmarried women aged between 15 and 19 years, and sexually active proportions of 15 to 19 year-old women who were married or unmarried, but sexually active compared to older women who were perceived to be sexually inactive. Findings of the study revealed that in most of the countries, the proportion of adolescent women using contraceptives had increased substantially and that the rate at which the contraceptive prevalence rate was increasing was faster among the adolescent than among older women.

Abiodun and Balogun (2009) carried out a study to determine the pattern of sexual behavior and contraceptive use among female students attending tertiary institutions in Nigeria. Data collected from self-administered and semi-structured questionnaires were used in the study. The findings of the study showed that although all the respondents were aware of contraceptives, only a quarter of them admitted to have ever used any contraceptive method. Friends/relatives were identified to be the most common source of information about contraceptives. Moreover, fear of side effects was identified as the reason for non-use of modern contraceptives. The study further revealed that the quality of contraceptives affected their uptake amongst female students attending tertiary institutions.

According to Okech et al. (2011), the Kenya government in collaboration with other stakeholders involved in the provision of family planning services have put in place various strategies and policies to increase uptake of family planning services. These are aimed at increasing contraceptive prevalence rate (CPR), reduction in both total fertility rate (TFR) and unmet need for family planning services. Despite the various strategies and policies, total fertility rate still remains high at 4.6 percent, while CPR and unmet need for family planning are estimated at 46 percent and 24 percent, respectively.

Ettarh and Kyobutungi (2012) in their study examined the spatial variation in modern contraceptive use and unmet need for family planning in Kenya. The study also examined whether the variations in contraceptive use were associated with inequalities in physical access to health facilities. Data from the 2008-2009 Kenya Demographic and Health Survey was used. Multivariate logistic regression was used to examine the influence of distance to the nearest health facility and health facility density, in addition to other covariates, on modern contraceptive use and unmet need. The findings of the study revealed that modern contraceptives use was significantly less among the respondents who lived more than $5 \mathrm{~km}$ from the nearest health facility compared to women who reside $5 \mathrm{~km}$ or less from the nearest health facility. In addition, women from counties with higher health facility density were $53 \%$ more likely to use modern contraceptives compared to those who live in counties with low health facility density. However, the distance and health facility density in the county were not significantly associated with unmet need.

Kidayi et al. (2015) examined the factors influencing modern contraceptive use among women aged 15 - 49 years in Tanzania. They employed secondary data source from the Tanzania Demographic Health Survey (TDHS), 2010. A total of 475 clusters (urban and rural) composed of 9663 households were selected. During the survey, a total of 10,139 women aged 15 - 49 years were interviewed about sexual and reproductive matters using a standardized questionnaire. They restricted their survey to married/cohabiting women $(n=6412)$ respondents for in individual records and domestic violence $(n=4471)$. The used the univariate and multiple logistic regression analyses to analyze the obtained data. The result of their findings revealed that Women empowerment $(\mathrm{OR}=1.4 ; 95 \% \mathrm{CI}: 1.13$ - 1.63), male-female age difference of less or equal to nine (OR = 1.6; $95 \mathrm{CI}$ : 1.01 - 2.66), and advice given at health care facilities on family planning (OR $=1.6 ; 95 \mathrm{CI}$ : 1.37 - 1.96) were predictors of modern contraceptive use. Woman sexual violence was not associated with modern contraceptive use. They concluded that the predictors of modern contraceptive use in their study corresponds with previous studies in low and middle income countries. Women empowerment, male-female age difference, and child desire were important predictors for modern contraceptive use. 


\section{METHODOLOGY}

\subsection{Source of Data}

The source of data for this study is primary source of data collection. This is obtained through descriptive cross sectional study carried out in the Oghara, Ethiope West Local Government Area, Delta State, Nigeria. The target population was the women of reproductive age group in the town.

A simple random sampling method of 400 respondents were administered questionnaire and out of the 400 questionnaires administered 387 were found to be adequate for the analysis. This is because 13 respondents did not properly respond to all the items in the questionnaire. The inclusion criteria for the respondents is that a woman will be eligible if she was resident and 15 years or more but less or equal to 49 years of age. This is reproductive age group of women.

\subsection{Logistic Regression}

The logistic regression is a statistical tool used in predicting categorical placement in a dependent variable or the probability of category membership on a dependent variable based on multiple independent variables. The independent variables can be either dichotomous (i.e., binary) or continuous (i.e., interval or ratio in scale). Logistic regression allows for two categories of the dependent or outcome variable (categories such as 0,1 or $-1,0$ ). The logistic regression uses maximum likelihood estimation to evaluate the probability of categorical membership. The logistic regression does necessitate careful consideration of the sample size and examination for outlying cases. Like other data analysis procedures, initial data analysis should be thorough and include careful univariate, bivariate, and multivariate assessment. Specifically, multicollinearity should be evaluated with simple correlations among the independent variables. Logistic regression is often considered an attractive analysis because it does not assume normality, linearity, or homoscedasticity. Logistic regression does have assumptions, such as the assumption of independence among the dependent variable choices. This assumption states that the choice of or membership in one category is not related to the choice or membership of another category (i.e., the dependent variable). The assumption of independence can be tested with the Hausman-McFadden test (Hoffmann, 2003).

Suppose we have $n$ independent observation with $p$ explanatory variables. The qualitative response variable has $\mathrm{k}$ categories. To construct the logits in the logistic case one of the categories is considered the base level and the other logits constructed relative to it. Any category can be taken as the base level, we shall take category k as the base level in our description of the method. Since there is no ordering, it is apparent that any category may be labeled $k$. Let $\pi_{j}$ denote the probability of an observation falling in the $\mathrm{j}^{\text {th }}$ category (Chattefuee and Hadi, 2006). To obtain the relationship between this probability and the $\mathrm{p}$ explanatory variables, $\mathrm{X}_{1}, \mathrm{X}_{2}, \ldots, \mathrm{X}_{\mathrm{p}}$. The logistic regression model is expressed as

$\log \left(\frac{\pi_{\mathrm{j}}\left(x_{\mathrm{i}}\right)}{\pi_{\mathrm{k}}\left(x_{\mathrm{i}}\right)}\right)=\beta_{0 \mathrm{j}}+\beta_{1 \mathrm{j}} x_{1 \mathrm{i}}+\beta_{2 \mathrm{j}} x_{2 \mathrm{i}}+\cdots+\beta_{\mathrm{pj}} x_{\mathrm{pi}}$

$$
\text { for } \mathrm{j}=1,2, \ldots,(\mathrm{k}-1) \text { and for } \mathrm{j}=1,2, \ldots, \mathrm{n}
$$

Letting all the $\pi^{\prime}$ s add to unity, (1) will then have the form

$$
\log \left(\pi_{\mathrm{j}}\left(x_{\mathrm{i}}\right)\right)=\frac{\exp \left(\beta_{0 \mathrm{j}}+\beta_{1 \mathrm{j}} x_{1 \mathrm{i}}+\beta_{2 \mathrm{j}} x_{2 \mathrm{i}}+\cdots+\beta_{\mathrm{pj}} x_{\mathrm{pi}}\right)}{1+\sum_{j=1}^{k-1} \exp \left(\beta_{0 \mathrm{j}}+\beta_{1 \mathrm{j}} x_{1 \mathrm{i}}+\beta_{2 \mathrm{j}} x_{2 \mathrm{i}}+\cdots+\beta_{\mathrm{pj}} x_{\mathrm{pi}}\right)}
$$

for $\mathrm{j}=1,2, \ldots,(\mathrm{k}-1)$.

\subsection{Model Specification}

We shall specify the logistic model required for estimating knowledge of contraceptives with demographic variables as predictors as 
Aronu, C. O. et. al., A Quantitative Survey on the knowledge and use of Contraceptive

$\log \left(\pi_{\mathrm{j}}\left(x_{\mathrm{i}}\right)\right)=\frac{1}{1+\exp -\left(\beta_{0}+\beta_{1} x_{1}+\beta_{2} x_{2}+\beta_{3} x_{3}+\beta_{4} x_{4}+\beta_{5} x_{5}+\beta_{6} x_{6}+\beta_{7} x_{7}\right)}$ (3)

Where $\pi_{\mathrm{j}}\left(x_{\mathrm{i}}\right)$ represents the probability of respondents having knowledge of contraceptives (Yes),

$\mathrm{X}_{1}$ represents Age of respondents,

$\mathrm{X}_{2}$ represents Marital Status of respondents,

$\mathrm{X}_{3}$ represents Religion of respondents,

$\mathrm{X}_{4}$ represents Occupation of respondents,

$\mathrm{X}_{5}$ represents highest level of education of respondents,

$\mathrm{X}_{6}$ represents response on current number of children and

$\mathrm{X}_{7}$ represents response on desired number of children

Similarly, the logistic model required for estimating use of contraceptives with demographic variables as predictors as

$\log \left(\pi_{\mathrm{k}}\left(x_{\mathrm{i}}\right)\right)=\frac{1}{1+\exp -\left(\beta_{0}+\beta_{1} x_{1}+\beta_{2} x_{2}+\beta_{3} x_{3}+\beta_{4} x_{4}+\beta_{5} x_{5}+\beta_{6} x_{6}+\beta_{7} x_{7}\right)}$ (4)

Where $\pi_{\mathrm{k}}\left(x_{\mathrm{i}}\right)$ represents the probability of respondents using contraceptives (Yes),

$\mathrm{X}_{1}$ represents Age of respondents,

$\mathrm{X}_{2}$ represents Marital Status of respondents,

$\mathrm{X}_{3}$ represents Religion of respondents,

$\mathrm{X}_{4}$ represents Occupation of respondents,

$\mathrm{X}_{5}$ represents highest level of education of respondents,

$\mathrm{X}_{6}$ represents response on current number of children and

$\mathrm{X}_{7}$ represents response on desired number of children

\subsection{DATA ANALYSIS}

4.1 Logistic Analysis on the impact of demographic variables on Knowledge of Contraceptive amongst women

Table 1: Model Summary for assessing the impact of demographic variables on Knowledge of Contraceptive amongst women

\begin{tabular}{|c|c|c|c|}
\hline Step & $\mathbf{- 2}$ Log likelihood & Cox \& Snell R Square & Nagelkerke R Square \\
\hline 1 & $458.257^{\mathrm{a}}$ & .101 & .139 \\
\hline
\end{tabular}

a. Estimation terminated at iteration number 4 because parameter estimates changed by less than .001 .

The result presented in table 1 found the Cox and Snell value of $10.1 \%$ which showed that the predictor variables were able to explain about $10.1 \%$ of total variation in the response variable knowledge of contraceptive. 
Table 2: Table showing classification of responses on Knowledge of Contraceptive amongst women in Anambra State

\begin{tabular}{|c|c|c|c|c|c|}
\hline & \multirow{3}{*}{ Observed } & & \multicolumn{3}{|c|}{ Predicted } \\
\hline & & & \multicolumn{2}{|c|}{$\begin{array}{c}\text { Have you heard about } \\
\text { contraceptives? }\end{array}$} & \multirow{2}{*}{$\begin{array}{l}\text { Percentage } \\
\text { Correct }\end{array}$} \\
\hline & & & Yes & No & \\
\hline \multirow{3}{*}{ Step 1} & \multirow{2}{*}{$\begin{array}{c}\text { Have you heard about } \\
\text { contraceptives? }\end{array}$} & Yes & 37 & 97 & 27.6 \\
\hline & & No & 51 & 202 & 79.8 \\
\hline & \multicolumn{2}{|c|}{ Overall Percentage } & & & 61.8 \\
\hline
\end{tabular}

a. The cut value is .500

The result obtained in table 2 revealed that $27.6 \%$ of the respondents who responded "Yes" have correctly heard about contraceptives while $79.8 \%$ of respondents that responded "No" were correct that they have not heard about contraceptive. Hence, the overall misclassification rate of $38.2 \%(100 \%-61.8 \%=38.2 \%)$.

Table 3: Table showing individual coefficients of the demographic variables on the Knowledge of Contraceptive amongst women

\begin{tabular}{|c|c|c|c|c|c|c|c|}
\hline & & B & S.E. & Wald & df & Sig. & $\operatorname{Exp}(B)$ \\
\hline \multirow{8}{*}{ Step $1^{a}$} & Age & -.323 & .093 & 12.037 & 1 & .001 & .724 \\
\hline & Marital_Status & .066 & .084 & .623 & 1 & .430 & 1.069 \\
\hline & Religion & -.152 & .325 & .218 & 1 & .641 & .859 \\
\hline & Occupation & -.244 & .261 & .872 & 1 & .350 & .784 \\
\hline & HLE & -.204 & .123 & 2.748 & 1 & .097 & .815 \\
\hline & Q7 & .239 & .180 & 1.765 & 1 & .184 & 1.270 \\
\hline & Q8 & .896 & .232 & 14.928 & 1 & .000 & 2.450 \\
\hline & Constant & -.348 & .977 & .127 & 1 & .722 & .706 \\
\hline
\end{tabular}

a. Variable(s) entered on step 1: Age, Marital_Status, Religion, Occupation, HLE, Q7, Q8.

The result obtained in table 3 showed that Age of respondents and response on desired number of children contributed significantly on the status of knowledge of contraceptive amongst women with coefficient values of -0.323 and 0.896 respectively with corresponding p-values of 0.001 and 0.00 which were less than critical value of 0.05 assuming $95 \%$ confidence level. Further result showed that their odds ratio were obtained as 0.724 and 2.450 respectively. This result implies that as the category of age increases by a unit, knowledge of contraceptive increases by $27.6 \%$ (since $\operatorname{Exp}(B)=0.724$ and $1-0.724=0.276$ ) while as category for the number of desired children increases by a unit, the knowledge of contraceptive becomes 2.45 times greater (since $\operatorname{Exp}(B)=2.45)$.

\subsection{Logistic Analysis on the impact of demographic variables on the use of Contraceptive amongst women}

Table 4: Model Summary for assessing the impact of demographic variables on the use of Contraceptive amongst women

\begin{tabular}{|c|c|c|c|}
\hline \multirow{2}{*}{ Step } & $\mathbf{- 2}$ Log likelihood & Cox \& Snell R Square & Nagelkerke R Square \\
\hline 1 & $336.682^{\mathrm{a}}$ & .156 & .241 \\
\hline
\end{tabular}

a. Estimation terminated at iteration number 5 because parameter estimates changed by less than .001. 
Aronu, C. O. et. al., A Quantitative Survey on the knowledge and use of Contraceptive ......

The result presented in table 4 found the Cox and Snell value of $15.6 \%$ which showed that the predictor variables were able to explain about $15.6 \%$ of total variation in the response variable usage of contraceptive.

Table 5: Table showing classification of responses on the use of Contraceptive amongst women

\begin{tabular}{|c|c|c|c|c|c|}
\hline & \multirow{3}{*}{ Observed } & & \multicolumn{3}{|c|}{ Predicted } \\
\hline & & & \multicolumn{2}{|c|}{ Do you use contraception regular? } & \multirow{2}{*}{$\begin{array}{c}\text { Percentage } \\
\text { Correct }\end{array}$} \\
\hline & & & Yes & No & \\
\hline \multirow{3}{*}{ Step 1} & Do you use contraception & Yes & 24 & 59 & 28.9 \\
\hline & regular? & No & 8 & 296 & 97.4 \\
\hline & \multicolumn{2}{|c|}{ Overall Percentage } & & & 82.7 \\
\hline
\end{tabular}

a. The cut value is .500

The result obtained in table 5 revealed $28.9 \%$ of respondents that said "Yes" correctly use contraceptives were actually correct while $97.4 \%$ of respondents that responded "No" were correct that they don't use contraceptives. Hence, the overall misclassification rate of $17.3 \%(100 \%-82.7 \%=17.3 \%)$.

Table 6: Table showing individual coefficients of the demographic variables on the use of Contraceptive amongst women

\begin{tabular}{|ll|r|r|r|r|r|r|}
\hline & B & S.E. & Wald & df & \multicolumn{1}{c|}{ Sig. } & Exp(B) \\
\hline Step 1 & Age & .145 & .122 & 1.408 & 1 & .235 & 1.156 \\
& Marital_Status & .701 & .137 & 26.249 & 1 & .000 & 2.015 \\
Religion & -1.202 & .341 & 12.402 & 1 & .000 & .301 \\
Occupation & -.340 & .330 & 1.067 & 1 & .302 & .711 \\
HLE & .350 & .148 & 5.640 & 1 & .018 & 1.420 \\
Q7 & -.415 & .249 & 2.783 & 1 & .095 & .660 \\
Q8 & .409 & .280 & 2.141 & 1 & .143 \\
Constant & .286 & 1.318 & .047 & 1 & .828 & 1.506 \\
\hline
\end{tabular}

a. Variable(s) entered on step 1: Age, Marital_Status, Religion, Occupation, HLE, Q7, Q8.

The result obtained in table 6 showed that Marital Status of respondents, Religion, and highest level of education contributed significantly on the status of usage of contraceptives amongst women with coefficient values of $0.701,-1.202$, and 0.350 respectively with corresponding p-values of $0.00,0.00$ and 0.018 which were less than the critical value of 0.05 assuming $95 \%$ confidence level. Also, their odds ratio value were obtained as 2.015, 0.301, and 1.420 respectively. This result implies that as the category of Marital status increases by a unit, usage of contraceptive becomes 2.015 times greater $(\operatorname{since} \operatorname{Exp}(B)=2.015)$, as category of religion of respondents increase by a unit, usage of contraceptives increases by $69.9 \%(\operatorname{since} \operatorname{Exp}(B)=0.301$ and 1 $0.301=0.699$ ), while as category of highest level of education increases by a unit, the usage of contraceptive becomes 1.42 times greater $($ since $\operatorname{Exp}(\mathrm{B})=1.42)$. 


\subsection{Descriptive Analysis on Demographic Response of the Respondents}

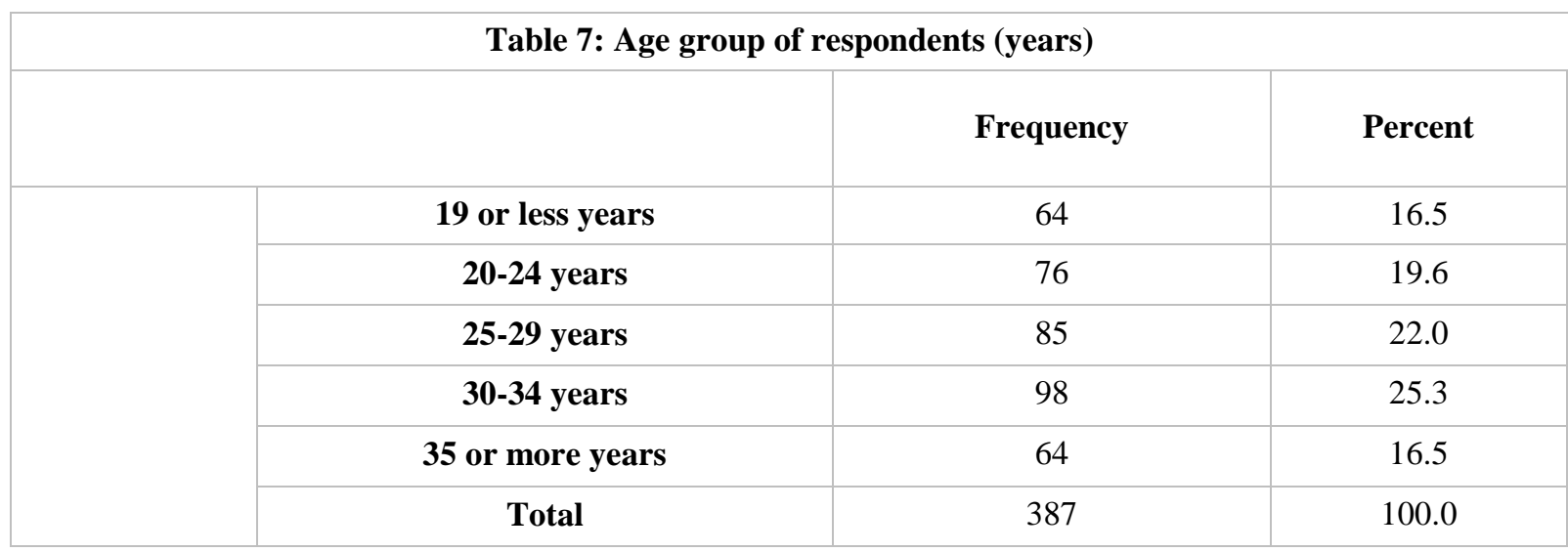

The result of the Age distribution showed that 25.3\% were aged 30-34 years, $22.0 \%$ aged 25-29 years, $19.6 \%$ aged $20-24$ years, $16.5 \%$ aged 35 or more years, and $16.5 \%$ aged 19 or less years. Hence, majority of the respondents were aged 30-34 years.

Table 8: Marital Status of respondents

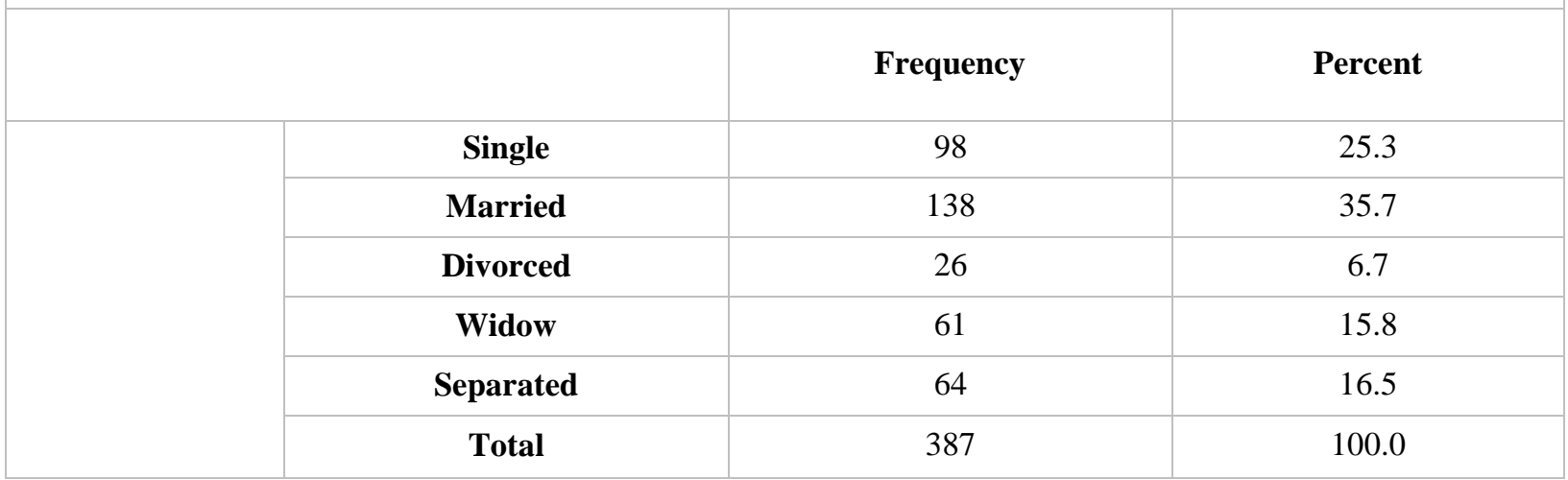

The result of the distribution of Marital status of the respondents, it was found that $35.7 \%$ were married, $25.3 \%$ were single, $16.5 \%$ were separated, $15.8 \%$ were widow, and $6.7 \%$ were divorced. The result showed that majority of the respondents were married.

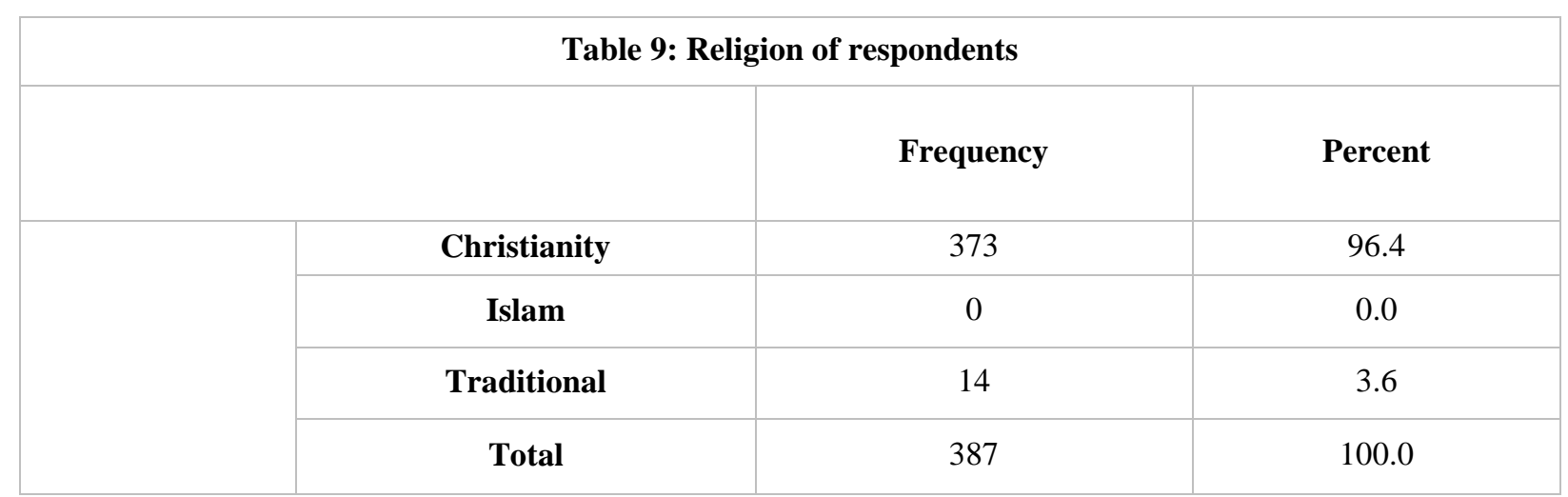

Result on responses on religion of respondents showed that $96.4 \%$ practice Christianity, $3.6 \%$ were Traditionalist and $0.0 \%$ were Muslim. The result showed that majority of the respondents were Christians. 
Aronu, C. O. et. al., A Quantitative Survey on the knowledge and use of Contraceptive

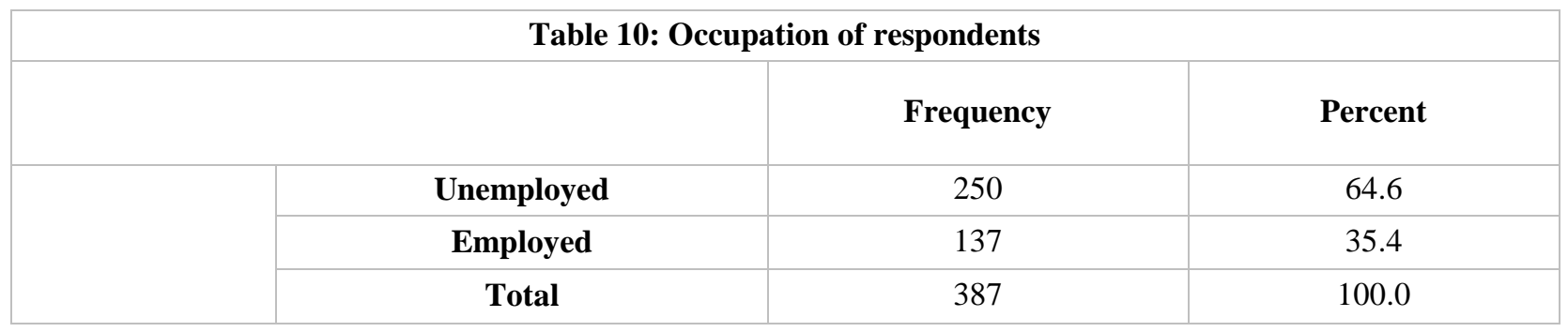

It was found that $64.6 \%$ of the respondents were unemployed while $35.4 \%$ were employed.

\begin{tabular}{|c|c|c|c|}
\hline \multicolumn{2}{|c|}{ Table 11: Highest Level of Education } \\
\hline & & Frequency & Percent \\
\hline & No formal education & 109 & 28.2 \\
\hline & Primary & 87 & 22.5 \\
\hline & Secondary & 158 & 40.8 \\
\hline & Tertiary & 33 & 8.5 \\
\hline & Total & 387 & 100.0 \\
\hline
\end{tabular}

The result of the distribution of educational level of the respondents showed that $40.8 \%$ attended secondary education, $28.2 \%$ have no formal education, $22.5 \%$ have primary education, and $8.5 \%$ have tertiary education. Hence, majority of the respondents had secondary education.

\begin{tabular}{|c|c|c|c|}
\hline \multicolumn{4}{|c|}{ Table 12: Question: Current Number of Children } \\
\hline \\
\cline { 2 - 3 } & Frequency & Percent \\
\hline & $\mathbf{0}$ & 46 & 11.9 \\
\hline & $\mathbf{1 - 4}$ & 147 & 38.0 \\
\hline & $\mathbf{4}$ & 194 & 50.1 \\
\hline & Total & 387 & 100.0 \\
\hline
\end{tabular}

It was found that $50.1 \%$ of the respondents currently have greater than 4 children, $38.0 \%$ have $1-4$ children while $11.9 \%$ have no children yet.

\begin{tabular}{|c|c|c|c|}
\hline \multicolumn{4}{|c|}{ Table 13: Question: Desired number of Children } \\
\hline & & Frequency & Percent \\
\hline & $\mathbf{0}$ & 0 & 0.0 \\
\hline & $\mathbf{1 - 4}$ & 181 & 46.8 \\
\hline & $\mathbf{4}$ & 206 & 53.2 \\
\hline & Total & 387 & 100.0 \\
\hline
\end{tabular}

Also, it was found that $53.2 \%$ of the respondents desire to have greater than 4 children, $46.8 \%$ desire to have $1-4$ children and none of them desired not to have children.

\section{CONCLUSION}

This study assesses the knowledge and use of contraceptive amongst women in Oghara, Delta State, Nigeria. It was found for the descriptive analysis of the demographic responses that majority of the respondents were aged 30-34 while majority of the respondents were married. It was found that majority of the respondents were Christians. Also, it was found that $64.6 \%$ of the respondents were unemployed while $35.4 \%$ were employed. The result of the distribution of educational level of the respondents 
showed that $40.8 \%$ attended secondary education, $28.2 \%$ have no formal education, $22.5 \%$ have primary education, and $8.5 \%$ have tertiary education. Hence, majority of the respondents had secondary education. It was found that $50.1 \%$ of the respondents currently have greater than 4 children, $38.0 \%$ have 1-4 children while $11.9 \%$ have no children yet. Also, it was found that $53.2 \%$ of the respondents desire to have greater than 4 children, $46.8 \%$ desire to have 1-4 children and none of them desired not to have children.

Findings revealed that the overall misclassification rate of knowledge of contraceptive among the respondents was $38.2 \%$ while the overall misclassification on use of contraceptive was $17.3 \%$ which implies that the response from the respondents on knowledge and use of contraceptive were reliable. It was found that demographic variables such as Age of respondents and response on desired number of children contributed significantly on the status of knowledge of contraceptive amongst women. Also, findings showed that that as the category of age increases by a unit, knowledge of contraceptive increases by $27.6 \%$ while as category for the number of desired children increases by a unit, the knowledge of contraceptive becomes 2.45 times greater. This result is line with findings by Kidayi et al. (2015) who identified child desire as one of the important predictor for modern contraceptive use in Tanzania.

Further findings revealed that demographic variables such as Marital Status of respondents, Religion, and highest level of education contributed significantly on the status of use of contraceptives amongst women. Also, it was found that as the category of Marital status increases by a unit, use of contraceptive becomes 2.015 times greater, while as category of religion of respondents increase by a unit, usage of contraceptives increases by $69.9 \%$, and as category of highest level of education increases by a unit, the usage of contraceptive becomes 1.42 times greater.

It was found that majority of the respondents don't have knowledge of contraceptive while very few who have the knowledge got the required knowledge through Print Media, Friend/relatives, Electronic media, and health personnel.

The findings of the present study revealed that majority of women in Oghara, Delta State don't have knowledge and equally don't use contraceptive, hence we recommend the need for sensitization of women on the benefits of contraceptives not only in the local government and also in most rural areas of the state.

\section{REFERENCES}

1. Abiodun, O. M. and Balogun, O. R. (2009). Sexual activity and contraceptive use among young female students of tertiary educational institutions in Ilorin, Nigeria. Contraception, 79: 146-149.

2. Bankole, A., Oye-Adeniran, B., Singh, S., Adewole, I. F., Wulf, D., et al. (2006). Unwanted Pregnancy and Unsafe Abortion in Nigeria: Causes and Consequences. New York: Guttmacher Institute.

3. Blumenthal, P. D., Voedisch, A., Gemzell-Danielsson, K. (2011). Strategies to prevent unintended pregnancy: increasing use of long-acting reversible contraception. Hum Reprod Update 17: 121-137.

4. Chattefuee, S. and Hadi, A. S. (2006). Regression Analysis by Example ( $4^{\text {th }}$ ed). A John Wiley \& Sons, Inc., Publication, Pp 329-339

5. Ettarh, R.R. and Kyobutungi. C. (2012). Physical access to health facilities and contraceptive use in Kenya: Evidence from the 2008-2009 Kenya Demographic and Health Survey. African Journal of Reproductive Health, 16(3): 47-54.

6. Hoffmann, J. (2003). Generalized linear models: An applied approach. Boston, MA: Allyn \& Bacon.

7. Kidayi, P.L., Msuya, S., Todd, J., Mtuya, C.C., Mtuy, T. and Mahande, M.J. (2015). Determinants of Modern Contraceptive Use among Women of Reproductive Age in Tanzania: Evidence from Tanzania Demographic and Health Survey Data. Advances in Sexual Medicine, 5, 43-52.

8. Monjok, E., Smesny, A., Ekabua, J.E., and Essien, J.E. (2010). Contraceptive practices in Nigeria: literature review and recommendation for future policy decisions. Open Access J Contracept, 1: 9-22

9. Okech, T. C., Wawire, N. W. and Mburu, T. K. (2011).Contraceptive Use among Women of Reproductive Age in Kenya's City Slums. International Journal of Business and Social Science, 2(1): 22-43.

10. Oringanje, C., Meremikwu, M. M., Eko, H., Esu, E., Meremikwu, A., et al. (2009) Interventions for preventing unintended pregnancies among adolescents. Cochrane Database Syst Rev: CD005215.

11. Rich-Edwards, J. (2002) Teen pregnancy is not a public health crisis in the United States. It is time we made it one. Int $J$ Epidemiol 31: 555-556.

12. Stephenson, R., Baschieri, A., Clements, S., Hennick, M., and Madise, N. (2007). Contextual Influences on modern contraceptive Use in Sub-Saharan Africa, American Journal of Public Health, 97(7): 1233-1240.

13. Tsui, A. O., Croft, T. N., and Trevitt, T. L. (2009). Patterns and Trends in Adolescents' Contraceptive Use and Discontinuation in Developing Countries and Comparisons with adult Women. International Perspectives On Sexual and Reproductive Health, 35(2): 63-71.

14. Tsui, A. O., McDonald-Mosley, R., and Burke, A. E. (2010). Family planning and the burden of unintended pregnancies. Epidemiol Rev, 32: 152-174. 


\section{APPENDIX}

Questionnaire for Assessment of Knowledge and Use of Contraceptives in Oghara, Delta State, Nigeria.

\section{SECTION A: DEMOGRAPHIC CHARACTERISTICS}

1. $\quad$ Age Group (in Years)

19 or less [ ] $20-24$ [ ] $25-29$ [ ] $30-34$ [ ] 35 or more [ ]

2. Marital Status

Single [ ] Married [ ] Divorced [ ] Widow [ ] Separated [ ]

3. Religion

Christianity [ ] Islam [ ] Traditional [ ]

4. Occupation

Unemployed [ ] Employed [ ]

5. Highest Level of Education

No Formal Education [ ] Primary [ ] Secondary [ ] Tertiary [ ]

6. Have you ever had sex?

Yes [ ] No[ ]

7. Current Number of Children?

0 [ ] 1-4 [ ] >4 [ ]

8. Desired Number of Children?

0 [ ] 1-4 [ ] >4 [ ]

\section{SECTION B: KNOWLEDGE OF CONTRACEPTION}

9. Have you heard about contraceptives?

Yes [ ] No [ ]

10. Who informed you about Contraceptive?

Friend/Relatives [ ]

Print Media (Postal, Hand bill) [ ]

Electronic Media (Radio/TV) [ ]

Health Personnel [ ]

Not Applicable []

11. Contraceptive is used for?

Prevention of unwanted Pregnancy [ ]

Increase Family Size [ ]

Prevent sexually transmitted diseases [ ]

All of the above [ ]

\section{SECTION C: USE OF CONTRACEPTION}

12. Do you use Contraception regular?

Yes [ ] No [ ]

13. Which of the Contraceptive Method do you use?

Condom [ ] Natural Method [ ] Pill [ ] Injection [ ] IUD [ ] Not Applicable [ ]

14. Do your Spouse approve of your use of Contraceptive?

Yes [ ] No [ ] Not Applicable [ ]

15. What duration of Contraception do you use (in years)?

1-5 [ ] 6-10 [ ] 11-15 [ ] 16-20 [ ] 21-25 [ ] Not Applicable [ ]

16. Which government facility do you access modern contraceptive services and

Hospital [ ] Health Centres [ ] Family planning clinic [ ] Outreach [ ]

commodities?

Private providers [ ] Not Applicable [ ]

Community distributors [ ] 